\title{
Perosomus elumbis em bovino: relato de caso*
}

\section{Perosomus elumbis in cattle: case report}

\section{Perosomus elumbis en bovinos: relato de caso}

\section{Paulo Felipe Izique Goiozo; ${ }^{1}$ Giovana Wingeter Di Santis;² Enio Pedone Bandarra ${ }^{3}$}

Serviço de Patologia Veterinária da Faculdade de Medicina Veterinária "Octávio Bastos" (UNIFEOB). São João da Boa Vista, SP, Brasil

\section{Resumo}

Objetivo: Descrever um caso de Perosomus elumbis, anomalia congênita raramente encontrada e de etiologia desconhecida. Descrição: Em um bezerro, macho, natimorto, Holandês, encaminhado para necropsia, constatou-se gênese anômala da coluna vertebral, caracterizada pela ausência das vértebras lombares, sacrais e coccígeas, bem como da medula espinhal a partir deste segmento. Apresentava, ainda, sete vértebras cervicais e seis torácicas, além de canal vertebral terminando em fundo cego. Mostrava, também, hipoplasia do coxal, artrogripose e atrofia da musculatura dos membros posteriores. Conclusões: As anomalias evidenciadas na necropsia comparadas aos dados da literatura permitiram o diagnóstico de Perosomus elumbis, uma anomalia congênita, rara, de etiologia desconhecida.

Palavras-chave: Coluna vertebral, anormalidades. Bovinos.

\footnotetext{
${ }^{1}$ Médico Veterinário. Bolsista de Aperfeiçoamento Técnico do CNPq/CNPGC/EMBRAPA, Campo Grande, MS. CRMV-MS 2841

${ }^{2}$ Doutoranda em Patologia Veterinária pela Faculdade de Medicina Veterinária e Zootecnia da Universidade Estadual Paulista (UNESP), Botucatu, SP. CRMV-SP 11.958 ${ }^{3}$ Professor Adjunto do programa de pós-graduação do Departamento de Clínica Veterinária da Faculdade de Medicina de Veterinária e Zootecnia da Universidade Estadual Paulista (UNESP), Botucatu, SP. Professor Doutor de Anatomia Patológica da Faculdade de Medicina Veterinária da UNIFEOB. CRMV-SP 0786

*Trabalho apresentado ao CONGRESSO BRASILEIRO DE MEDICINA VETERINÁRIA, 29., 2002, Gramado, RS
} 


\section{Introdução}

Perosomus elumbis é uma anomalia congênita, raramente encontrada, representando menos de $1 \%$ de todas as anomalias congênitas dos bovinos, ${ }^{1}$ de etiologia desconhecida, caracterizada por agenesia parcial da medula espinhal e ausência de vértebras lombares, sacrais e coccígeas, se traduzindo por encurtamento do corpo do animal e atrofia especialmente dos membros posteriores..$^{2-5}$

O processo já foi descrito em bovinos, ovinos e suínos. ${ }^{2,4,6,7}$ Este erro de morfogenia representa um conjunto de alterações em que, basicamente, a parte anterior do corpo é normal e o eixo vertebral termina na região torácica caudal em um canal cego, não existindo as vértebras lombares, sacrais e coccígeas. Essa malformação comumente está associada à artrogripose e à atrofia muscular dos membros posteriores..$^{3-5,8}$

\section{Descrição do Caso}

Um bezerro natimorto, Holandês preto e branco, removido por cesariana, foi encaminhado ao Serviço de Patologia Veterinária da Faculdade de Medicina Veterinária “Octávio Bastos”, no município de São João da Boa Vista, SP. O animal foi submetido ao exame necroscópico segundo as técnicas de rotina e, posteriormente, em virtude dos achados, foi macerado para melhor visualização das estruturas ósseas (Figura 1).

Ao exame externo, observou-se feto com características de feto a termo, chamando a atenção a ausência de cauda, artrogripose e atrofia dos membros posteriores, e à palpação, ausência de coluna vertebral a partir do segmento torácico (Figura 2).

Durante a necropsia procedeu-se a exame detalhado da coluna vertebral. Esta, constatou-se, era composta por sete vértebras cervicais e seis torácicas, das quais apenas as três primeiras apresentavam processos espinhosos e todas possuíam costelas, havendo oito no lado esquerdo (com quarta e sexta costelas bífidas) e sete no direito (com terceira costela bífida). O canal vertebral terminava em fundo cego com ausência das vértebras lombares, sacrais e coccígeas, bem como da medula espinhal a partir desse segmento (Figura 3). Mostrava ainda hipoplasia

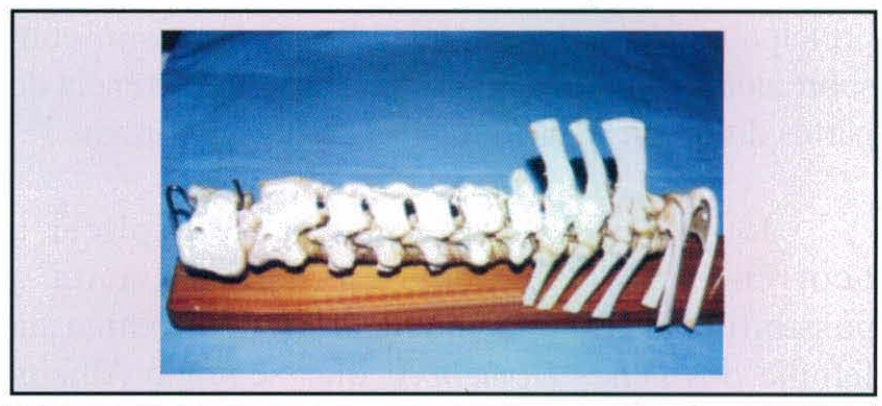

Figura 1 - Coluna vertebral após a maceração. Observar a presença das sete vértebras cervicais e apenas seis torácicas, terminando em fundo cego

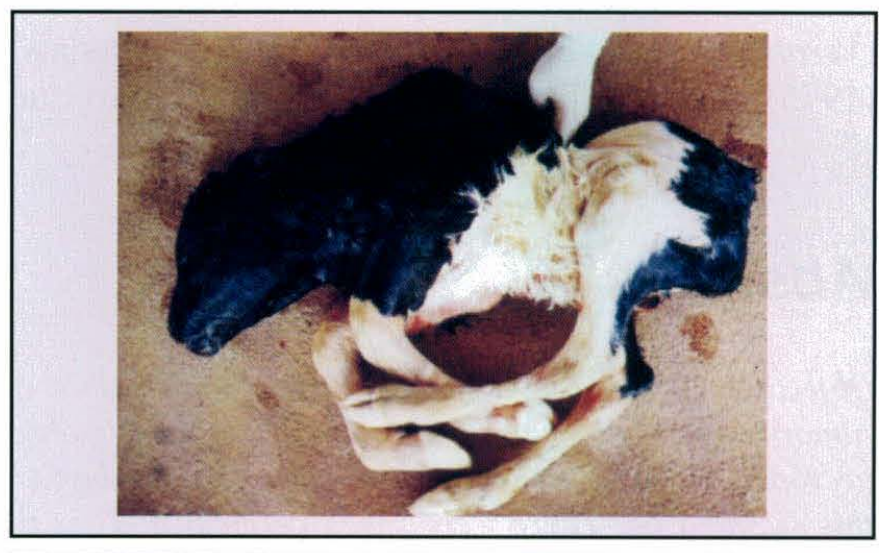

Figura 2 - Aspectọ externo de animal com Perosomus elumbis. Observar ausência de cauda, artrogripose, atrofia dos membros posteriores, e ausência de coluna vertebral a partir do segmento torácico mediante a palpação

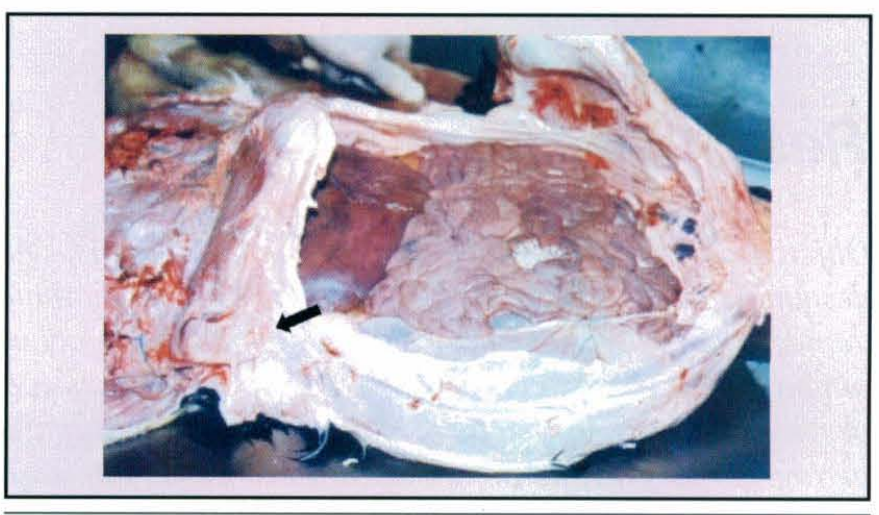

Figura 3 - Término da coluna vertebral em fundo cego (seta) e ausência das vértebras subseqüentes ao segmento torácico 
do coxal, artrogripose e atrofia da musculatura dos membros posteriores.

\section{Discussão e Conclusões}

Em bovinos, essa anomalia acomete principalmente as raças Holandesa e Hereford, com sobrevida máxima de dois dias, sendo a ocorrência de partos distócicos mais freqüente do que os normais. ${ }^{4,6,9}$

Jones $^{4}$ (1999), na tentativa de explicar a ocorrência do Perosomus elumbis, aventa a possibilidade de uma mutação cromossômica na família dos genes Homeobox que, segundo Alberts et al. ${ }^{8}$ (1997), mostram-se geralmente alterados nas anomalias do crescimento de origem conhecida.

Em ovinos da raça Merino, a ingestão de plantas (Veratrum californicum) foi considerada por Dennis ${ }^{7}$ (1975) como uma das causas dessa malformação, que apresentou uma incidência de $0,18 \%$ em 4.417 cordeiros examinados.

Os resultados do exame necroscópico, comparados aos dados da literatura, permitiram concluir tratar-se de um caso de Perosomus elumbis, anomalia congênita rara de etiologia ainda desconhecida. Porém, deve-se levar em consideração as afirmações de Jones ${ }^{4}$ (1999) de que essa anomalia provavelmente apresenta ligação com a seqüência dos genes Homeobox que, de acordo com Alberts et. al. ${ }^{8}$ (1997), só se manifesta nos casos de anomalias do crescimento. Em bovinos, os raros casos descritos são em animais das raças Holandesa e Hereford, natimortos ou com sobrevida de no máximo dois dias, o que coincide com os achados do presente relato. Tendo em vista a raridade e a escassez de informações referentes a esse processo, o presente trabalho visa adicionar dados à literatura pertinente, contribuindo dessa maneira com a casuística nacional.

\section{Abstract}

Objective: To describe a case of Perosomus elumbis, a rare congenital anomaly of unknown etiology. Description: Abnormal formation of the vertebral column was observed in a stillborn male Holstein-Friesian calf referred for necropsy, characterized by the absence of the lumbar, sacral and coccigeal vertebrae, as well as the spinal cord from this segment on. There were seven cervical and six thoracic vertebrae, and the vertebral channel ended blindly. Hypoplasia of the coxal bone, arthrogryposis and muscular atrophy of the pelvic limbs were also noted. Conclusions: The confrontation of the lesions observed in necropsy with data found in literature led to the diagnosis of Perosomus elumbis, a rare congenital anomaly of unknown etiology.

Keywords: Spine cords, abnormalities. Bovine.

\section{Resumen}

Objetivo: Describir un caso de Perosomus elumbis, una anomalía congénita, raramente encontrada y de etiología desconocida. Descripción: En un becerro macho natimuerto de raza holandesa, encaminado para los procedimientos de necroscopia, se constató génesis anómala de la columna vertebral, caracterizada por la ausencia de las vértebras lumbares, sacrales y coccígeas, así como de la médula espinal a partir de este segmento, presencia de siete vértebras cervicales y seis torácicas y canal vertebral terminando en fondo ciego. Mostraba incluso hipoplasia del coxal, artrogriposis y atrofia de la musculatura de los miembros posteriores. Conclusiones: Las anomalías evidenciadas en la necropsia comparadas a los datos de la literatura permitieron el diagnóstico de perosomus elumbis, una anomalía congénita, rara, de etiología desconocida.

Palabras- clave: Columna vertebral, anomalía. Bovinos. 


\section{Referências}

1. CASTRO, M. B.; HOKAMURA, H. K.; ROMANO, M. A. Perosomus elumbis in a Holstein calf in Franca, SP. In: ENCONTRO NACIONAL DE PATOLOGIA VETERINÁRIA, 10., 2001, Pirassununga. Anais... Pirassununga: ENAPAVE, 2001. p. 211.

2. KITT, T. et al. Malformaciones. In: Tratado de patología general veterinaria. Barcelona: Labor, 1954. p. 419-440.

3. JUBB, K. V. F.; HUXTABLE, C. R. Perosomus elumbis. In: JUBB, K. V. F.; KENNEDY, P. C.; PALMER, N. (Eds.). Pathology of domestic animals. San Diego: Academic Press, 1993. v. 1, p. 276.

4. JONES, C. J. Perosomus elumbis (vertebral agenesis and arthrogryposis) in a stillborn Holstein calf. Veterinary Pathology, v. 36, p. 64-70, 1999.
5. WOODARD, J. C. Sistema esquelético. In: JONES, T. C.; HUNT, R. D.; KING, N. W. (Eds.). Patologia veterinária. 6. ed. São Paulo: Manole, 2000. p. 945-946.

6. GREENE, H. J.; LEIPOLD, H. W.; DENNIS, S. M. Perosomus elumbis in Hereford calves. Veterinary Medical Small Animal Clinical, v. 68, p. 167-168, 1973.

7. DENNIS, S. M. Perosomus elumbis in sheep. Australian Veterinary Journal, v. 51, p. 135-136, 1975.

8. ALBERTS, B. et al. Biologia molecular da célula. 3. ed. Porto Alegre: Artes Médicas, 1997. 1293 p.

9. BALASUBRAMANIAN, S. et al. Live perosomus elumbis, monster and its successful delivery per vaginum in a cow: a case report. Indian Veterinary Journal, v. 68, p. 677-678, 1991. 